GLASILO

FUTURE

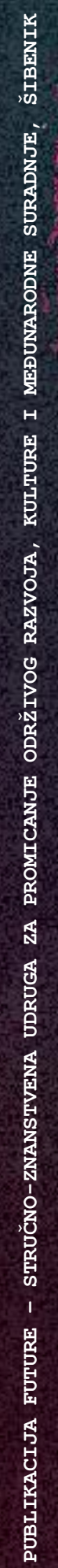

VOLUMEN 1 BROJ 5-6

PROSINAC 2018.

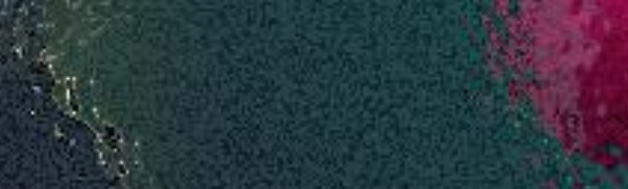

UDK 60

UDK 631

UDK 630

UDK 336

UDK 338
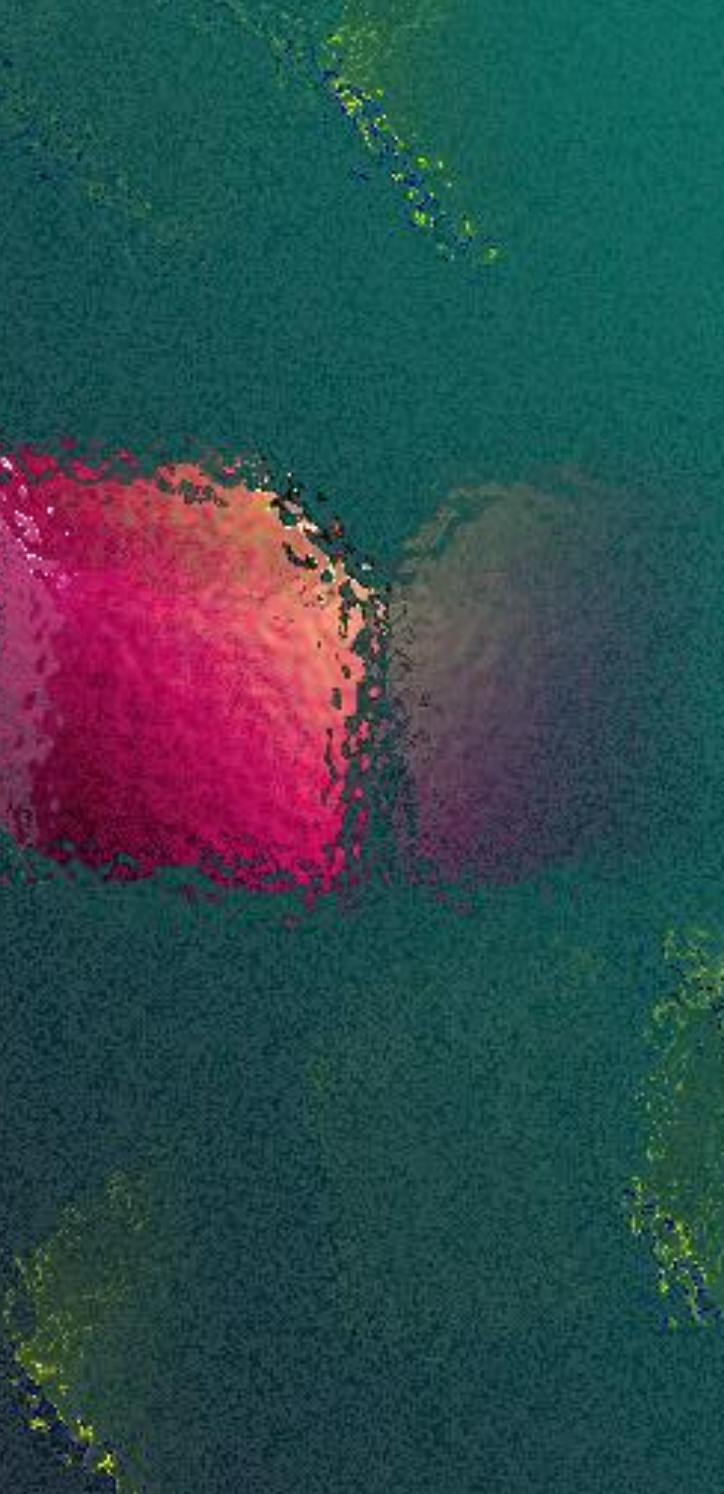


\section{Glasilo Future}

\section{Stručno-znanstveni časopis}

Nakladnik: FUTURA

\section{FUTUR}

Sjedište udruge: Šibenik

\section{Adresa uredništva:}

Bana Josipa Jelačića 13 a, 22000 Šibenik, Hrvatska / Croatia 留 / 圆: +385 (0) 022218133

$\triangle$ : urednistvo@gazette-future.eu / editors@gazette-future.eu (3): www.gazette-future.eu

\section{Uređivački odbor / Editorial Board:}

Doc. dr. sc. Boris Dorbić, v. pred. - glavni i odgovorni urednik / Editor-in-Chief

Emilija Friganović, dipl. ing. preh. teh., v. pred. - zamjenica g. i o. urednika / Deputy Editor-in-Chief

Ančica Sečan Matijaščić, mag. act. soc. - tehnička urednica / Technical Editor

Antonia Dorbić, mag. art. - zamjenica tehničke urednice / Deputy Technical Editor

Prof. dr. sc. Željko Španjol

Mr. sc. Milivoj Blažević

Vesna Štibrić, dipl. ing. preh. teh.

\section{Međunarodno uredništvo / International Editorial Board:}

Prof. dr. sc. Kiril Bahcevandziev - Portugal (Instituto Politécnico de Coimbra)

Prof. dr. sc. Martin Bobinac - Srbija (Šumarski fakultet Beograd)

Doc. dr. sc. Zvezda Bogevska - Makedonija (Fakultet za zemjodelski nauki i hrana Skopje)

Dario Bognolo, mag. ing. - Hrvatska (Veleučilište u Rijeci)

Prof. dr. sc. Agata Cieszewska - Poljska (Szkoła Główna Gospodarstwa Wiejskiego w Warszawie)

Dr. sc. Bogdan Cvjetković, prof. emeritus - Hrvatska (Agronomski fakultet Zagreb)

Prof. dr. sc. Duška Ćurić - Hrvatska (Prehrambeno-biotehnološki fakultet Zagreb)

Doc. dr. sc. Margarita Davitkovska - Makedonija (Fakultet za zemjodelski nauki i hrana Skopje)

Doc. dr. sc. Dubravka Dujmović Purgar - Hrvatska (Agronomski fakultet Zagreb)

Prof. dr. sc. Semina Hadžiabulić - Bosna i Hercegovina (Agromediteranski fakultet Mostar)

Prof. dr. sc. Péter Honfi - Mađarska (Faculty of Horticultural Science Budapest)

Prof. dr. sc. Valeria Ivanova - Bugarska (Fakultet za lozaro-gradinarstvo Plovdiv)

Doc. dr. sc. Orhan Jašić - Bosna i Hercegovina (Filozofski fakultet Tuzla)

Prof. dr. sc. Tajana Krička - Hrvatska (Agronomski fakultet Zagreb)

Prof. dr. sc. Biljana Lazović - Crna Gora (Biotehnički fakultet Podgorica)

Prof. dr. sc. Bosiljka Mustać - Hrvatska (Sveučilište u Zadru)

Hrv. akademik prof. dr. sc. Stanislav Nakić - Bosna i Hercegovina (Sveučilište Hercegovina Mostar)

Sandra Popović, mag. ing. - Srbija (Poljoprivredni fakultet Beograd)

Doc. dr. sc. Bojan Simovski - Makedonija (Šumarski fakultet Skopje)

Prof. dr. sc. Davor Skejić - Hrvatska (Građevinski fakultet Zagreb)

Doc. dr. sc. Milan Stanković - Srbija (Univerzitet u Kragujevcu)

Akademik prof. dr. sc. Refik Šećibović - Bosna i Hercegovina (Visoka škola za turizam i menadžment Konjic)

Prof. dr. sc. Andrej Šušek - Slovenija (Fakulteta za kmetijstvo in biosistemske vede Maribor)

Prof. dr. sc. Elma Temim - Bosna i Hercegovina (Agromediteranski fakultet Mostar)

Doc. dr. sc. Ivana Vitasović Kosić - Hrvatska (Agronomski fakultet Zagreb)

Doc. dr. sc. Ana Vujošević - Srbija (Poljoprivredni fakultet Beograd)

Prof. dr. sc. Vesna Židovec - Hrvatska (Agronomski fakultet Zagreb)

Lektura i grafička priprema: Ančica Sečan Matijaščić, mag. act. soc.

Objavljeno: 31. prosinca 2018. godine.

Časopis izlazi u elektroničkom izdanju dva puta godišnje, krajem lipnja i prosinca, a predviđena su i dva interdisciplinarna specijalna izdanja tijekom godine iz STEM i ostalih znanstvenih/umjetničkih područja.

Časopis je besplatan. Rukopisi i recenzije se ne vraćaju i ne honoriraju.

Umnožavanje (reproduciranje), stavljanje u promet (distribuiranje), priopćavanje javnosti, stavljanje na raspolaganje javnosti odnosno prerada u bilo kojem obliku nije dopuštena bez pismenog dopuštenja Nakladnika. Sadržaj objavljen u Glasilu Future može se slobodno koristiti u osobne i obrazovne svrhe uz obvezno navođenje izvora. 


\section{Glasilo Future}

\section{Stručno-znanstveni časopis}

FUTURA - stručno-znanstvena udruga za promicanje održivog razvoja, kulture i međunarodne suradnje, Bana Josipa Jelačića 13 a, 22000 Šibenik, Hrvatska

(2018) $1(5-6) 01-52$

\section{SADRŽAJ:}

\section{Izvorni znanstveni rad (original scientific paper)}

Str.

B. Dorbić, Lea Zemunović, Tea Zemunović, Emilija Friganović, Elma Temim, Katica Arar

Istraživanje općih saznanja o nekim vrstama trajnica na Mediteranu

A research on common knowledge about some perennial species in the Mediterranean region

Branka Stipanović

Stavovi maslinara o podizanju konkurentnosti maslinarstva u Dalmaciji u kontekstu ARISTOIL projekta

Attitudes of olive growers in Dalmatia region about competiveness growth in context of ARISTOIL project

\section{Stručni rad (professional paper)}

\section{Blažević}

Ogled o urbanim i prirodnim vrijednosnicama Šibenika u kontekstu turističke perspektive

An overview of urban and natural values of Šibenik in the context and from tourism perspective

J. E. Meeker, Z. Lišnić, B. Dorbić, Emilija Friganović, Ž. Španjol, Zvezda Bogevska Mogućnosti uporabe nekih jestivih submediteranskih autohtonih i alohtonih vrsta za održive dekorativne vrtove na kršu

Opportunities for use of some edible sub-Mediterranean autochthonous and allochthonous species for sustainable ornamental gardens in karst landscapes

\section{Nekategorizirani rad (uncategorised paper)}

\section{Zdenka Bilušić}

Vijesti

News 
J. E. Meeker, Z. Lišnić, B. Dorbić, Emilija Friganović, Ž. Španjol, Zvezda Bogevska / Mogućnosti uporabe nekih jestivih submediteranskih autohtonih i alohtonih vrsta za ... / Glasilo Future (2018) 1 (5-6) 41-48

\title{
Mogućnosti uporabe nekih jestivih submediteranskih autohtonih i alohtonih vrsta za održive dekorativne vrtove na kršu
}

\section{Opportunities for use of some edible sub-Mediterranean autochthonous and allochthonous species for sustainable ornamental gardens in karst landscapes}

\author{
Jonathan Eric Meeker $^{1,2}$, Zvonimir Lišnić ${ }^{1,2}$, Boris Dorbić ${ }^{1 *}$, Emilija Friganović ${ }^{1}$, \\ Željko Španjol ${ }^{3}$, Zvezda Bogevska $^{4}$
}

stručni rad (professional paper)

doi: 10.32779/gf.1.5-6.4

\section{Sažetak}

U novije vrijeme zbog suvremenog načina života i troškova održavanja u gradskom i prigradskom okruženju na submediteranu smanjila se brojnost i veličina klasičnih vrtova s ukrasnim biljem. Ipak, u zadnje vrijeme mogli bismo reći da raste trend osnivanja samoodrživih vrtova i misija kako očuvati biološku raznolikost na krajobraznim površinama. U ovom radu se razmatraju mogućnosti primjene i opisuju neke jestive alohtone i autohtone vrste za održive vrtove na submediteranskom kršu. Cilj rada je odabrati adekvatne biljne vrste da budu dekorativne i iskoristive za ljudsku prehranu (kao voće, povrće, ljekovito i aromatično bilje). Obrađuju se vrste iz različitih porodica: Aliaceae, Asparagaceae, Berberidaceae, Brassicaceae, Cactaceae, Cupressaceae, Campanulaceae, Ericaceae, Lamiaceae, Liliaceae, Orchidaceae, Portulaceae i Rosaceae. U nekim vrtovima na submediteranu tako se mogu pronaći divlje jagode, maline ili kupine koje se mogu lijepo ukomponirati na ukrasnu kamenjaru ili na ukrasnu gredicu. Aromatične i ljekovite vrste: kadulja, lavanda, smilje, ružmarin, timijan, paprena metvica, ružmarin i slično itekako su poželjne u formiranju održivih vrtova na kršu. U ukrasnoj hortikulturi česta je primjena vrsta s krša (osobito onih nižeg rasta) i na dekorativnim kamenjarama u vrtovima ili na nekim drugim krajobraznim površinama. Određene biljne vrste s većih nadmorskih visina se ne mogu zbog loše prilagodbe na agroekološke uvjete uzgajati u nižim područjima. U nekim planinskim područjima česti su primjeri uporabe alpinetuma koji se uređuju s vrstama $\mathrm{s}$ viših nadmorskih visina.

Ključne riječi: jestive biljne vrste, održivi vrtovi, primjena, krš, submediteran.

\footnotetext{
${ }^{1}$ Veleučilište "Marko Marulić" u Kninu, Krešimirova 30, 22300 Knin, Republika Hrvatska.

* Doc. dr. sc. Boris Dorbić, v. pred., e-mail: bdorbic@veleknin.hr.

${ }^{2}$ Studenti preddiplomskog stručnog studija Poljoprivreda krša, smjer: Biljna proizvodnja.

${ }^{3}$ Šumarski fakultet Sveučilišta u Zagrebu, Svetošimunska c. 25, 10000 Zagreb, Republika Hrvatska.

${ }^{4}$ Univerzitet Sv. Kiril i Metodij, Fakultet za zemjodelski nauki i hrana Skopje, 16-ta Makedonska brigada 3, 1000 Skopje, Republika Makedonija.
} 


\section{Abstract}

The number and size of classical gardens with ornamental plants has recently decreased, as a result of the modern lifestyle and maintenance costs in urban and suburban environments in the sub-Mediterranean region. Nevertheless, it is important to highlight the fact that we have recently seen a growing trend of establishing self-sustaining gardens and initiatives intended to preserve biological diversity in landscape areas. This paper considers the opportunities for use and it provides a description of several edible autochthonous and allochthonous species for sustainable ornamental gardens in sub-Mediterranean karst landscapes. The objective of the paper is to select adequate plant species that are both ornamental and edible (such as fruit, vegetables, medicinal and aromatic plants). Species from different families have been analyzed, such as Aliaceae, Asparagaceae, Berberidaceae, Brassicaceae, Cactaceae, Cupressaceae, Campanulaceae, Ericaceae, Lamiaceae, Liliaceae, Orchidaceae, Portulaceae and Rosaceae. Hence, in some gardens in sub-Mediterranean areas, one can come across wild strawberries, raspberries or blueberries which can be nicely incorporated into ornamental rock gardens or decorative raised beds. Aromatic and medicinal species include sage, lavender, immortelles, rosemary, thyme and peppermint, among others. They are highly desirable in the formation of sustainable gardens in karst landscapes. Species typical in karst landscapes (primarily those of low height) are frequently used in ornamental horticulture, as well as in ornamental rock gardens or in some other landscape areas. Specific plant species typical at higher altitudes cannot be grown at lower altitudes due to their poor adjustment to agro-ecological conditions. In some mountainous areas frequent instances of use of Alpinetum have been identified, which is used for landscaping with species typical of higher altitudes.

Key words: edible plant species, sustainable gardens, use, karst, sub-Mediterranean.

\section{Uvod}

Zbog suvremenog načina života u gradskom i prigradskom okruženju na submediteranu smanjila se brojnost i veličina "klasičnih" vrtova s ukrasnim biljem. Zahvaljujući europskom nasljeđu umjerenih zona za uređenje i oblikovanje vrtova i krajobraznih površina dugo su prevladavale egzotične biljne vrste s velikom potrebom za vodom (O'Brien, 1996).

U zadnjem desetljeću javlja se trend osnivanja "samoodrživih" vrtova i misija kako očuvati biološku raznolikost na krajobraznim površinama. Također je u trendu uvođenje i primjena autohtonih biljaka (Židovec i Karlović, 2005; Dorbić et al., 2012). U radu se razmatraju mogućnosti primjene i opisuju neke jestive alohotne i autohtone vrste za potonje. 
Reljefna i klimatska obličja Hrvatske doprinijela su razvoju velikog broja različitih biljnih vrsta. Ljekovito i aromatično bilje uvijek je imalo ulogu u narodnoj medicini. Dalmacija obiluje ljekovitim i aromatičnim biljem, kako u primorskom dijelu tako i zaleđu te Zagori (Roša et al., 2009, prema Dorbić et al., 2016).

Upotreba samoniklog (nekultiviranog) povrća duž Mediteranskog dijela Hrvatske još je relativno česta, premda je u opadanju, kao i u cijeloj Europi i svijetu. Neke vrste osim što se koriste za jelo, mogu biti dekorativni element u vrtu: Asparagus acutifolius L. - šparoga, Ruscus aculeatus L. veprina, Allium ursinum L. - medvjeđi luk, Papaver rhoeas L. - divlji mak, Equisetum arvense L. preslica, Salvia officinalis L. - kadulja (Vitasović Kosić, 2018).

Razlog opadanju korištenja samonikloga divljeg bilja na globalnoj razini valja tražiti u velikoj dostupnosti i opskrbi kultiviranim biljkama posvuda kako u Svijetu, tako i u Hrvatskoj, kao i u pristupu lako dostupnim novim znanjima te razmjenom znanja putem Interneta. Domena u kojoj je ta promjena najvidljivija je upravo korištenje divljeg zelja odnosno lisnatog povrća (Dolina et al., 2016, prema Vitasović Kosić, 2018).

Cilj rada je odabrati adekvatne biljne vrste da budu dekorativne i iskoristive za ljudsku prehranu. $\mathrm{U}$ ukrasnoj hortikulturi česta je primjena vrsta s krša (osobito onih nižeg rasta) i na dekorativnim kamenjarama u vrtovima ili na nekim drugim krajobraznim površinama. Neke biljne vrste $\mathrm{s}$ većih nadmorskih visina se ne mogu prilagoditi agroekološkim uvjetima uzgoja u nižim područjima.

\section{Odabrane vrste jestivog bilja za primjenu u dekorativnim vrtovima na kršu}

U daljnjem tekstu obrađuju se odabrane vrste jestivog bilja (po porodicama) koje svoju primjenu mogu pronaći u dekorativnim vrtovima na kršu.

\section{Alliaceae - Allium spp. (osobito: Allium carinatum L., Allium karataviense Regel, Allium schoenoprasum L., Allium triquetrum L., Allium ursinum L., Allium vineale L. i dr.)}

Karakteristika svih lukova je da dobro popunjavaju prostor. Cvijet i habitus nekih vrsta je veoma ukrasan. Za ljudsku prehranu se koristi list i lukovica. Lukovi su bogati vitaminom C. Uglavnom se mogu uzgajati u svim našim klimatima. U krajobrazu se mogu koristiti kod formiranja cvjetnih gredica, za obrube, živice itd.

\section{Asparagaceae - Hosta sp., Asparagus officinalis L.}

Hosta sp. - hosta posjeduje ukrasan cvijet, ali se uglavnom uzgaja kao vrsta dekorativnog lista. Mladi izdanci mogu se jesti kao kuhano povrće. U Japanu se konzumira kao razne vrste šparoga. Razmnožava se generativno, a biljka sama popunjava prostor generativnim ili vegetativnim načinom razmnožavanja. Biljka preferira polusjenu. Hosta spp. - hosta je biljka za kontinentalnu ili 
submediteransku klimu. U krajobrazu se može koristiti pojedinačno ili u grupama. A. officinalis šparoga se uzgaja kao vrsta dekorativnog habitusa i ukrasnih plodova (bobice). Mladi izdanci se jedu kao kuhani. Bobice su otrovne. Razmnožava se generativno ili vegetativno. Porijeklom je s Mediterana, ali uspijeva i na kontinentu (Lešić et al., 2002). U vrtu se koristi za pojedinačnu sadnju ili za grupe.

\section{Berberidaceae - Mahonia aquifolium (Pursh) Nutt.}

M. aquifolium - mahonija. Dekorativni je grm visine do $1,5 \mathrm{~m}$, razgranat. Cvjetovi su žute boje i formiraju grozdaste cvatove. Plod je plava jestiva boba koja se može koristi za bojanje vina. Razmnožava se generativno i vegetativno. Biljka se najviše koristi kao parkovna vrsta na kontinentu i submediteranu. Koristi se za sadnju u skupinama, pojedinačno ili za živice (Šilić, 1991).

\section{Brassicaceae - Lepidium meyenii Walp.}

L. meyenii - maka je biljna vrsta iz Južne Amerike, koja nije u upotrebi kao ukrasna biljka, ali bi se mogla uzgajati i koristiti u planinskom i kontinentalnom području prvenstveno zbog ukrasnog zadebljalog hipokotila. Biljka ima dekorativnu bazalnu rozetu. List je jestiv, ali se prvenstveno koristi kao začin jer je ljut. Razmnožava se isključivo generativno (Gligić, 1953).

Cactaceae - Opuntia humifusa Raf., Opuntia fragilis (Nutt.) Haw., Opuntia ficus-indica (L.) Mill., Maihuenia poeppigii (Otto ex Pfeiffer) Phil. ex K. Schum

O. humifusa, O. fragilis, O. ficus-indica. Polegnuta i lomljiva opuncija. Spada u sukulente. Jestivi su joj i listovi, koji imaju okus na jabuku. Plod se također konzumira. Polegnuta je bolja vrsta za uzgoj kod nas, zbog toga što bolje podnosi našu vlažnu klimu (premda traži dobru drenažu i sunčani položaj). Za razliku od većine kaktusa, ove dvije vrste podnose niske temperature. Sjeme se sije iz ploda ili se koriste lisne reznice koje se najprije moraju na suncu sušiti nekoliko dana (LLIFLE, 2005 - 2019). U vrtu se sadi pojedinačno ili u grupama, koristi se i za ukrasne kamenjare. M. poeppigii, maihuén kaktus je manjeg rasta od opuncije, a plod mu je jednake veličine, žute boje. Plod je ukrasan, biljka brzo prekriva tlo. Ima dugu tradiciju kulinarske upotrebe. Samo se plod upotrebljava za jelo. Dobro podnosi niske temperature, ali ne i vlagu na kontinentu, pa je uzgoj ograničen na mediteransko područje. Razmnožava se vegetativno ili generativno. U vrtu se koristi kao i Opuntia (Belov, 2007b).

\section{Campanulaceae - Campanula rapunculus $\mathbf{L}$.}

C. rapunculus - zvončić ima ukrasan cvijet. Jede se list i bijeli korijen. Neke inozemne sjemenarske tvrtke imaju proizvodnju sjemena raznih kultivara zvončića za upotrebu kao povrće. Cvijet ima dugu cvjetnu stapku koja je kod kultiviranog oblika niska. Koristi se isključivo na kontinentu uz navodnjavanje (Dalebö, 2010). U skupinama različitih ljetnica dolazi kao dekor u vrtu. 


\section{Cupressaceae - Juniperus communis L.}

J. communis (osobito J. communis. ssp. alpina) borovica je srednje visok grm, visine do $1 \mathrm{~m}$, dekorativnog izgleda. Plave bobice su jestive i koriste se kao začin (za mesna jela ili alkoholna pića). Razmnožava se sjemenom i vegetativno. J. communis - borovica raste na kontinentu i na Mediteranu. Može se saditi pojedinačno, u skupinama, na kamenjarama ili za živice.

\section{Ericaceae - Gaultheria caespitosa Poepp. \& Edl., Vaccinium myrtillus L.}

G. caespitosa je biljna vrsta niskog rasta koja stvara po tlu pokrivač, a ima i ukrasne plodove. Raste na vlažnim staništima i u sjeni. Stvara bijele bobice koje su jestive. Od njih se može raditi pekmez. Razmnožava se vegetativno (Belov, 2007a). V. myrtillus, oxycoccos - borovnica, brusnica je planinska drvenasta biljka. Ima jestive ukusne bobice koje su ujedno i ukrasne. Vrsta preferira kiselo tlo, premda borovnica dobro uspijeva i na neutralnom tlu. Razmnožava se generativno i vegetativno. Najbolje raste na kontinentu, ali podnosi i mediteransku klimu uz navodnjavanje.

\section{Lamiaceae - Melissa officinalis L., Mentha sp. Origanum vulgare L., Origanum majorana L.,} Rosmarinus officinalis L., Salvia officinalis L., Thymus vulgaris $\mathbf{L}$.

M. officinalis - matičnjak se uzgaja za pripremu biljnog čaj i kao začin. Vrlo često se uzgaja na kršu. Mentha sp. - metvica se uzgaja za čaj i kao začin, a često se uzgaja na kamenjarama. $O$. vulgare, $O$. majorana - origano, majoran podnosi niže temperature nego majoran, pa je zato bolja vrsta za kontinentalnu klimu. Vrlo je korisna vrsta za tlopokrivač. List mu se koristi kao začin. U vrtu se koriste kao manji polugrmovi u skupinama. $R$. officinalis - ružmarin je grm niskoga rasta mediteranskoga porijekla. Ukrasan je zbog svojih ljubičastih cvjetića, a koristi se i list kao začin. Razlikuje se od navedenih vrsta iz porodice Lamiaceae po tome što je grm, pa ima drugačiju estetsku ulogu na ukrasnim kamenjarama i vrtovima. S. officinalis - kadulja. List joj se koristi kao začin, a vrsta ima i mnogo ukrasnih kultivara. Često se uzgaja na kamenjarama. T. vulgaris - timijan vrlo je sličan mažuranu.

\section{Liliaceae; Orchidaceae - Erythronium dens-canis L., Orchis spp. osobito Orchis mascula L., Orchis militaris L.}

E. dens-canis - zeljasta trajnica s duguljastom podzemnom lukovicom i nadzemnom visokom stabljikom s dva dugačka lista s grimiznim ili smeđim pjegama, te jednim visećim cvijetom ružičaste, crvenoljubičaste ili bijele (rijetko) boje sa 6 listića ocvijeća, najčešće previnutima unatrag, zbog kojih nalikuje ciklami (LZMK, 1990 - 2009). Listovi su jestivi, mogu se konzumirati sirovi ili kuhani, a lukovice se zbog visokog udjela škroba mogu sušiti, mljeti i koristiti kao brašno ili se kuhaju (Grlić, 1990). Pasji zub je u Hrvatskoj osjetljiva i zakonom zaštićena biljka. O. morio - mali kaćuni vrsta je dekorativnog ružičastog cvijeta koji nalikuje papučici. Za prehranu ljudi koristi se gomolj i to osušen i 
mljeven, najčešće za salep. To je vrlo popularan napitak na Balkanu i u Maloj Aziji. Cvijet je vrlo ukrasan. Za uzgoj iz sjemena potrebna je prije sjetve inokulacija simbiotskim organizmima. Biljka je sunčanih staništa, a traži i mnogo vode, tako da najbolje uspijeva na mediteranskim kamenjarima. Razmnožava se vegetativno gomoljima.

\section{Portulacaceae - Portulaca oleracea L.}

P. oleracea - tušt. Ovaj sukulent nije posebno ukrasna biljka, ali se može koristiti kao sporedni biljni element na ukrasnoj kamenjari. Stabljike i listovi se koriste za salatu ili se kisele. Umjereno je bogat vitaminom C (333 mg na $100 \mathrm{~g}$ ), ali i vitaminom A. Biljka najbolje raste na Mediteranu, ali nema većih problema za rast i na kontinentu. Podnosi sušne periode bez kiše (Duke i Avensu, 1985).

\section{Rosaceae - Fragaria spp., Rosa rugosa Thunb., Rubus chamaemorus L.}

Fragaria spp. (osobito $F$. vesca, $F$. $x$ ananassa). Divlja i pitoma jagoda. Koristi se plod koji je i dekorativan. Biljka se razmnožava pomoću vriježa, a i generativno sjemenom. Prednost pitome jagode F. $x$ annanasa je u veličini ploda, ali plod divlje jagode zna imati aromatičniji okus. Jagoda je ukrasna i zbog cvijeta. Plod je najčešće crven, ali ima i kultivara s bijelim plodovima (Wu et al., 2012). $R$. rugosa - japanska ruža potječe iz istočne Azije (Kina, Japan, Koreja). Razgranati je grm visine do $150 \mathrm{~cm}$. Jestiv je i plod koji je bogat vitaminom C. Cvjetovi i plodovi su krupni i dekorativni. Razmnožava se generativno i vegetativno (Gligić, 1953). Ova vrsta se može uzgajati na kontinentu i Mediteranu. $R$. chamaemorus - maroška se uzgaja zbog narančastog ploda koji se konzumira kao voće. Biljka je arktičkog staništa pa najbolje odgovara za naše planinske kamenjare, ali uspijeva i na kontinentu. Dobro uspijeva u Lici, a još bolje na krškim planinskim masivima. Zahtijeva kisela do neutralna tla i navodnjavanje. Preferira sunčana staništa (Fern, n.d.).

\section{Zaključak}

Opisane vrste iz navedenih porodica kao autohtone ili alohtone vrste mogu se prikladno ukomponirati u održive submediteranske vrtove na kršu. Navedene vrste se mogu koristiti za ljudsku prehranu i biti dekorativni element $u$ vrtu ili na krajobraznoj površini. Od alohtonih su odabrane manje poznate vrste koje se mogu koristiti i kao voćne i povrtne vrste, a uz to pružati i dekorativni efekt na zelenoj površini (Rubus chamaemorus, Erythronium dens-canis, Gaultheria caespitosa, Opuntia humifusa itd.) Takove vrste pružaju i niz mogućnosti za znanstvena istraživanja u našim agro-ekološkim područjima. U krajobrazu se mogu koristiti kao pokrivači tla, pojedinačne vrste odnosno za živicu, obrube na travnjacima, ukrasnu kamenjaru, grupe itd. Dobra adaptacija vrste na neko stanište rezultira i manjom upotrebom agrokemikalija i biljno-uzgojnih zahvata. 
J. E. Meeker, Z. Lišnić, B. Dorbić, Emilija Friganović, Ž. Španjol, Zvezda Bogevska / Mogućnosti uporabe nekih jestivih submediteranskih autohtonih i alohtonih vrsta za ... / Glasilo Future (2018) 1 (5-6) 41-48

\section{Zahvala}

Rad je izrađen u okviru seminarskih radova studenata Jonathana Erica Meekera i Zvonimira Lišnića s preddiplomskog stručnog studija Poljoprivreda krša smjer Biljna proizvodnja na Veleučilištu "Marko Marulić" u Kninu.

\section{Literatura}

Belov, M. ur. (2007a). Gaultheria caespitosa. Posjećeno 02. 09. 2018. na mrežnoj stranici Flora Chileana: http://www.chileflora.com/Florachilena/FloraEnglish/HighResPages/EH0079.htm

Belov, M. ur. (2007b). Maihuenia poeppigii. Posjećeno 05. 09. 2018. na mrežnoj stranici Flora Chileana: http://www.chileflora.com/Florachilena/FloraEnglish/HighResPages/EH0044.htm.

Dalebö, M. (2010). How to grow Rampion. Posjećeno 05. 09. 2018. na mrežnoj stranici Malcolm Dalebö: https://worcesterallotment.wordpress.com/2010/08/31/how-to-grow-rampion/.

Dolina, K., Jug-Dujaković, M., Łuczaj, Ł., Vitasović-Kosić, I. (2016). A century of changes in wild food plant use in coastal Croatia: the example of Krk and Poljica. Acta Soc Bot Pol. 85(3), 3508. http://dx.doi.org/10.5586/ asbp.3508.

Dorbić, B., Gaćina, N., Krnčević, M., Krnčević, Ž., Srpak, M. (2012). Krajobrazno uređenje i zaštita ruralnog okoliša starokršćanske crkve Srima-Prižba kod Šibenika s posebnim osvrtom na gastronomske vrijednosti u svrhu turističke valorizacije. Zbornik radova Međimurskog veleučilišta u Čakovcu, 3(2), 23-31.

Dorbić, B., Davitkovska, M., Temim, E., Pamuković, A. (2018). Ukrasno bilje - Uzgoj i primjena. Šibenik: Ogranak Matice hrvatske u Šibeniku.

Duke, A., Avensu, E. (1985). Medicinal Plants of China. Michigan: Reference Publications Inc.

Fern. K. ur. (n.d.). Rubus chamaemorus. Posjećeno 02. 09. 2018. na mrežnoj stranici Plants For A Future: https://pfaf.org/user/Plant.aspx?LatinName=Rubus+chamaemorus.

Gligić, V. (1953). Etimološki botanički rečnik. Sarajevo: Veselin Masleša.

Grlić, Lj. (1990). Enciklopedija samoniklog ljekovitog bilja. Zagreb: August Cesarec.

Lešić, R., Borošić, J., Buturac, I., Herak Ćustić, M., Poljak, M. (2002). Povrćarstvo. Čakovec: Zrinski. LLIFLE (2005 - 2019). Opuntia humifusa. Posjećeno 02. 09. 2018. na mrežnoj stranici LLIFLE Encyclopedia of Cacti: http://lifle.com/Encyclopedia/CACTI/Family/Cactaceae/11629/Opuntia_ humifusa. 
J. E. Meeker, Z. Lišnić, B. Dorbić, Emilija Friganović, Ž. Španjol, Zvezda Bogevska / Mogućnosti uporabe nekih jestivih submediteranskih autohtonih i alohtonih vrsta za ... / Glasilo Future (2018) 1 (5-6) 41-48

LZMK (1990 - 2009). Pasji trn. Posjećeno 02. 09. 2018. na mrežnoj stranici Hrvatske enciklopedije (Zagreb: Leksikografski zavod Miroslava Krleže): http://www.enciklopedija.hr/Natuknica.aspx? $\mathrm{ID}=42870$.

O'Brien, B. C. (1996). Xeriscaping: Sources of New Native Ornamental Plants. U: Janick, J. (ur.). Progress in new crops (str. 536-539). Arlington, Virginia: ASHS Press.

Šilić, Ć. (1991). Ukrasno drveće i grmlje. Sarajevo: Svjetlost.

Šiljković, Ž., Rimanić, A. (2005). Geographic aspects of medicinal plants organic growing in Croatia. Geoadria, 10(1), 53.

Vitasović-Kosić, I. (2018). Tradicionalna upotreba samoniklog jestivog bilja na području općine Kršan (Istra, Hrvatska). Glasilo Future, 1(1-2), 1-14.

Wu, F., Guan, Z., Whidden, A. (2012). Strawberry Industry Overview and Outlook. Florida: University of Florida Press.

Židovec, V., Karlović, K. (2005). Primjena autohtonog bilja u uređenju gradskog prostora. Agronomski glasnik, 67(2-4), 151-158.

Primljeno: 18. prosinca 2018. godine Received: December 18, 2018

Prihvaćeno: 31 . prosinca 2018. godine Accepted: December 31, 2018 